\title{
Nominal Adjustment Regimes in an Evolutionary Macrodynamics*
}

Gilberto Tadeu Lima**

Jaylson Jair da Silveira ${ }^{* * *}$

\begin{abstract}
We develop a satisficing evolutionary dynamics to provide microfoundations for (in)complete nominal adjustment. A firm can either pay a cost to update its information set and establish the optimal price (Nash strategy) or make use, without a cost, of past knowledge and try to set a price which is as close as possible to the optimal one (bounded rationality strategy). In a version without mutation, we show that only pure strategy equilibria (survival of only one strategy) emerge, although complete nominal adjustment, and thus money neutrality, is obtained in either case. As for stability, the equilibrium with extinction of Nash (bounded rationality) firms is a local attractor (repulser). In a version with mutation, in turn, while there are only mixed strategy equilibria (survival of both strategies), money is likewise neutral. And in case there is only one equilibrium, it is a local attractor. Besides, the mixed strategy equilibria of the version with mutation become two pure strategy equilibria when the mutation rate tends to zero.
\end{abstract}

Keywords: Price Rigidity, Money Neutrality, Bounded Rationality, Satisficing Evolutionary Dynamics.

JEL Codes: C73, D43, D83.

\footnotetext{
${ }^{*}$ Submitted in February 2007. Revised in March 2008. We are grateful to Gustavo Barros and to two referees for their comments, which allowed us to improve the paper. We also thank Fapesp and CNPq for their support. We take full responsibility for the design and content of the present version.

${ }^{* *}$ Department of Economics and Complex Research Group, FEA-USP. E-mail: giltadeu@usp.br

*** Department of Economics and Complex Research Group, FEA-RP-USP.

E-mail: jaylson@usp.br
} 


\section{Introduction}

Nominal and real impacts of aggregate demand variations have been extensively and intensely analyzed and debated in economic theory. In the presence of complete nominal adjustment, all of the variation in aggregate demand will have been absorbed in the form of a variation of the same sign and magnitude in the general price level. Therefore, the accommodation of at least some part of a change in aggregate demand in the form of output variability necessarily involves some nominal price rigidity, i.e., incomplete nominal adjustment.

One may say that nowadays most economists agree that a variation in aggregate demand, caused for instance by monetary policy, influences output, at least temporarily, and determines inflation, at least in the long run. It is worth noting that nominal price adjustment triggered by monetary changes, although not instantaneous, winds up being complete over time. Therefore, money neutrality, even though it can be violated in the short run, necessarily prevails in the long run.

This paper describes a macrodynamic model which, based on evolutionary game theory, provides microfoundations for nominal (in)complete adjustment. In a monopolistic economy, a firm can either pay a cost to update its information set and establish the optimal price (Nash strategy) or make use, without a cost, of past knowledge and try to set a price which is as close as possible to the optimal one (bounded rationality strategy), possibly losing profits. We assume that firms have a satisficing ${ }^{1}$ behavior when they choose between these two price-setting strategies. Based on this behavior, we then derive an evolutionary dynamics which, by interacting with macroeconomic dynamics, determines a change in the proportion in which these price-setting strategies are adopted by firms. Thus, such distribution of strategies evolves together with the macroeconomic variables in whose determination it participates. We show that the survival of the Nash strategy is not a sine qua non for complete nominal adjustment in the long run, i.e., the economy tends to an equilibrium in which there are only bounded rationality firms and where money is nonetheless neutral in the long run.

In a version without mutation, we show that only pure strategy equilibria (survival of only one strategy) emerge, although complete nominal adjustment, and thus money neutrality, is obtained in either case. As for stability, the equilibrium with extinction of Nash (bounded rationality) firms is a local attractor (repulser). In a version with mutation, in turn, while there are only mixed strategy equilibria (survival of both strategies), money is likewise neutral. And in case there is only one equilibrium, it will be a local attractor.

\footnotetext{
${ }^{1}$ In the words of this author (Simon, 1987, p. 243): "A decision maker who chooses the best available alternative according to some criterion is said to optimize; one who chooses an alternative that meets or exceeds specified criteria, but that is not guaranteed to be either unique or in any sense the best, is said to satisfice".
} 
The remainder of the paper is organized as follows. Section 2 presents most major empirical evidence of price rigidity described in the literature and provides a brief summary of the major attempts at using microfoundations to explain incomplete nominal adjustment. Section 3 provides the price-setting model for heterogeneous firms and derives the impact of monetary changes on a given distribution of strategies. Section 4 derives a satisficing evolutionary dynamics without mutation and analyzes the properties of the strategy distribution equilibria, besides the level of completeness of nominal adjustment in each one of them. Section 5 derives a satisficing evolutionary dynamics with mutation. The last section presents some final remarks.

\section{Literature Review}

There is ample empirical evidence that prices are not so flexible to instantly guarantee complete nominal adjustments in response to monetary changes. Taylor (1999) reports some of this evidence, most of which concerns the United States. First, his study shows that prices and wages are not perfectly flexible and that the variations have the same average annual frequency. Secondly, there is immense sectoral heterogeneity in the determination of prices and wages. Thirdly, this determination is not a synchronized process, but an interpolated one instead. Finally, the frequency in price and wage movements varies positively with the inflation rate. ${ }^{2}$ Bils and Klenov (2004) used broader U.S. data than those employed in previous studies and found a higher frequency in price movements, although relatively lower than that which characterizes prices as flexible: half of the prices had a median duration of around 4.3 months. With the exclusion of temporary promotional reductions in prices, half of the prices show a median duration of approximately 5.5 months.

For Canada, the empirical study by Amirault et al. (2006), based on a questionnaire filled out by a sample of firms, revealed that the prices of $50 \%$ of these firms have a median duration of 3 months, although the modal frequency is the same one observed for the United States by Bils and Klenov (2004), i.e., once a year. With regard to the euro area, Álvares et al. (2006) amassed microeconomic evidence underlying the prices at the consumer's level (10 countries) and at the producer's level ( 5 countries), in addition to the information collected through questionnaires answered by a sample of firms (9 countries), and detected a series of stylized facts, among which we highlight the following:

\footnotetext{
${ }^{2}$ Considering the purpose of the present paper, the following observation made by Taylor (1999) is pertinent: "One might hope that a model with homogeneous 'representative' price setting would be a good approximation to this more complex world, but most likely some degree of heterogeneity will be required to describe reality accurately" (p. 1020-21). In the subsequent model, it should be underscored that the heterogeneous behavior of price setting is a crucial element, coevolving with the macroeconomic variables (price level and real output).
} 
1. Firms change their prices, on average, once a year;

2. There exists considerable sectoral heterogeneity regarding price setting;

3. Price reductions are common, and there is no evidence of strong rigidity in such a reduction; and

4. The coexistence of two types of price setters regarding the relevant time horizon, namely the forward-looking and the backward-looking types.

There have been several attempts at providing microfoundations for incomplete nominal adjustment, especially in the new-Keynesian literature. Lucas (1972, 1973) introduced a pioneering attempt in the neoclassical tradition for the explanation of nonneutrality of money, based on the assumption of imperfect information on the price system in the presence of a monetary shock, which would lead rational agents to mistake fluctuations in the general price level for fluctuations in relative prices.

Thereafter, there were some contributions based on infrequent wage adjustments - and, by extension, on infrequent price adjustments (especially, Fischer (1977); Taylor (1980)). This would be the result of formal or implicit wage contracts, according to which changes in nominal aggregate demand would have temporary effects on real output. While the versions of these authors were based on time-dependent price-setting rules, in which adjustments take place only in predefined periods, Caplin and Spulber (1987) used a price rule that relied upon the state of the economy, the so-called Ss rule, to show that the interpolation of price adjustments might not be sufficient to produce nonneutrality of money. In fact, the authors show that even if only a fraction of firms adjusts their prices in response to a monetary shock, they can do it to such an extent that they produce a complete nominal adjustment to the general price level. However, most of the subsequent developments regarding the impacts of monetary policy that use interpolation of adjustments employed time-dependent adjustment rules. In this case, the choice has often been Calvo's (1983) formulation, in which the arrival process of the specific adjustment period is a random one.

The subsequent cycle was characterized by contributions based on the existence of price adjustment costs in monopolistic markets (mainly, Rotemberg (1982); Akerlof and Yellen (1985); Mankiw (1985); Blanchard and Kiyotaki (1987)). For instance, Akerlof and Yellen (1985) develop a model in which some price setters follow the rule of thumb of keeping prices constant after a demand shock caused by a variation in money supply. The major implication of the model is that the losses of firms that react like this to a monetary change are of second order, whereas there is a concomitant first-order impact on output. Since the loss represented by the deviation from complete optimization is of second order, the authors label the firms with such a behavior as "quasi-rational". 
More recently, Mankiw and Reis (2002) have developed a dynamic price-setting model based on the assumption that information does not spread instantly among agents. Although agents are rational, the information acquisition or (re)optimization costs slow down the disclosure of information about macroeconomic conditions. In the presence of such costs, although prices are constantly changing they are not always set based on all existing information. ${ }^{3}$ Hence, this contribution is labeled rigid information model instead of sticky price model. Specifically, a fraction of the population is assumed to update their information set about the current state of the economy in each period and to compute optimal prices based on this updated set. The remainder of the population continues to set the prices based on a dated information set. Therefore, the model combines elements of Calvo's (1983) random adjustment model with Lucas's (1973) imperfect information model.

The major intention of Mankiw and Reis (2002) was to develop an incomplete nominal adjustment model that could be an alternative to the sticky price model (standard at the time), which generated a forward-looking new-Keynesian Phillips curve - i.e., current inflation depends on a current output gap measure and on the current expectation of future inflation (Roberts, 1995). The search for this alternative model was justified by the fact that this Phillips curve has two implications that are questionable from an empirical standpoint: the price level shows persistence, but the inflation rate does not, and a credible disinflation is followed by output growth. In fact, the Phillips curve derived from the rigid information model has more plausible implications since, as in Fischer (1977), the relevant expectations for the determination of current inflation are the past expectations for current economic conditions - instead of a sticky price model, i.e., the current expectations for future economic conditions. ${ }^{4}$

\footnotetext{
${ }^{3}$ As empirical evidence of the importance of these costs, Mankiw and Reis (2002) cite the results reported and analyzed by Zbaracki et al. (2004), still in an unpublished version. Actually, Zbaracki et al. (2004) provide microeconomic evidence that these costs associated with (re)optimization are much more important than the conventional menu costs. In addition to physical costs (menu costs), three types of management costs are identified and measured (costs for information acquisition, decision-making and communication) and two types of consumer costs (communication and negotiation costs). Based on data from a large U.S. manufacturing company and from its consumers, management (consumer) costs are six (twenty) times greater than menu costs. The price setting costs amount to $1.22 \%$ of revenues and to $20.03 \%$ of the company's net margin.

${ }^{4}$ Given the aim of the present paper, one should note the suggestive observation made by Mankiw and Reis (2002) about the microfoundations for incomplete nominal adjustment: "In the end, microfoundations for the Phillips curve may require a better understanding of bounded rationality" (p. 1317). The final conclusion of the authors is also suggestive: "Yet we must admit that information processing is more complex than the time-contingent adjustment assumed here. Models of bounded rationality are notoriously difficult, but it seems clear that when circumstances change in large and obvious ways, people alter the mental resources they devote to learning and thinking about the new aspects of the world. Developing better models of how quickly people incorporate information about monetary policy into their plans, and why their
} 
Carroll (2006) proposes a new and interesting approach to the expectations formation process, based on epidemiology, in which only a small group of agents (fully rational professional forecasters) formulates its own expectations, which are then spread amidst the population by news media. However, not all agents pay constant and careful attention to macroeconomic news. These agents are assumed to absorb the economic contents of the news in a probabilistic manner, analogously to the dissemination of a disease in a population. So, the news about changes in macroeconomic conditions takes some time to be absorbed by the other agents.

Carroll (2006) shows that this model has a good empirical performance in explaining the dynamics of inflation and unemployment expectations. According to him, while Mankiw and Reis (2002) do not provide explicit microfoundations for their assumption of informational costs, his model does so based on epidemiological models for an aggregate expectational equation. As a matter of fact, the author derives an expectational equation identical with that one proposed by Mankiw and Reis (2002), except for the fact that in the latter the agents who update their expectations do it after formulating their own rational forecasts about the future course of macroeconomics, and not after they get information about professional forecasts through the news media.

Another interesting contribution in this recent line of imperfect information models was developed by Woodford (2003), based on the assumption that the agent has a limited capacity for absorbing information. Given that price setters learn about monetary policy through this limited information channel, it is as if they looked at the monetary policy with a random error and had therefore to solve a sign extraction problem à la Lucas (1973). Thus, a basic difference between the contributions of Mankiw and Reis (2002) and of Woodford (2003) concerns the way whereby the agents get the information. Whereas in the latter the price setters receive a signal with noise, in each period, about the monetary policy, in the former one, they get perfect information about the monetary policy in a given time period with a certain probability. ${ }^{5}$

response is faster at some times than others, may prove a fruitful avenue for future research on inflation-output dynamics" (p. 1319). An essential element of the dynamic model developed in what follows constitutes a bounded rationality behavior at the price setting level that is not subject to a mechanical rule for the updating of the information set, as in the model proposed by Mankiw and Reis (2002), in which a specification à la Calvo (1983) is adopted - where the period for price adjustment is random and therefore it is not a decision variable of the firm. In the subsequent model, the decision on price adjustment is taken continuously based on the possibilities of expected net (cost) benefits.

${ }^{5}$ Eichenbaum and Fisher (2004) interpret the price setting mechanism à la Calvo (1983) as a way to capture the firms' responses to several costs related to price movement. In the presence of these costs, firms fully optimize their costs only on a regular basis, following simple adjustment rules for the other periods. The types of costs associated with optimization borne in mind by the authors refer to costs with information acquisition, decision making, negotiation and communication, which differ from menu costs - which apply to all prices. As empirical evidence of these optimization costs, the authors cite Zbaracki et al. (2004), whose major results were reported in footnote 3 . 
With regard to evolutionary approaches towards which the model developed in the present paper seeks to contribute, two recent studies should be mentioned. The first one concerns the contribution of Bonomo et al. (2003), who use evolutionary game theory to analyze the output costs associated with disinflation, which is regarded as the transition between two stationary equilibria. After a monetary contraction, while some agents immediately adopt a new optimal price, corresponding to the new rational expectations equilibrium, other agents continue to use the strategy that was optimal for the previous monetary behavior. However, this discrepant behavior has a cost that is proportional to those agents who establish their prices according to the new monetary behavior, in which the evolutionary dynamics of strategy revision, the so-called replication strategy, makes the agents who continue to use the previous strategy asymptotically disappear. ${ }^{6}$ Thus, the population of agents will converge to the new rational expectations equilibrium, corresponding to the new monetary behavior in the long run - i.e., all agents will adopt the new Nash strategy.

The second evolutionary contribution is that by Saint-Paul (2005). ${ }^{7}$ Seeking to find an explanation to price rigidity, the author assesses to what extent, if any, a rigid price setting strategy results from the equilibrium of an economy constituted of imperfectly rational agents. These agents are assumed not to be able to compute their optimal price setting rule, thus having to employ rules of thumb. Nevertheless, since firms replace rules that produce a low payoff with those that yield a high payoff, a question that is naturally raised is concerned with whether this macroeconomics converges to a rational expectations equilibrium (or to a Nash equilibrium, as referenced in the present paper), in which nominal adjustment of the general price level is complete and, therefore, monetary change does not affect output. Firms are affected by the behavior of other firms in that such behavior affects the aggregate price level. Another important component of the model refers to a type of local interaction, which is a simple local productive externality that implies that the payoff function of an agent depends on the price chosen by a contiguous agent.

Saint-Paul (2005) demonstrates that although the strategy corresponding to the rational expectations equilibrium is among those that could be used by the agents, the economy does not tend towards that equilibrium for an interval of parameters. Instead, the economy converges to an equilibrium in which the general price level does not react equally to contemporaneous monetary shocks, as with the rational expectations equilibrium. Nonetheless, money will be nearly neutral in the long run if the autocorrelation of monetary shocks is high. Therefore, price rigidity derives from the combination of two factors, namely, a low variation in

\footnotetext{
${ }^{6}$ In this dynamics, strategies with performance lower than the mean are proportionately less adopted.

${ }^{7}$ Although the author states that his paper is the first one to deal with price level rigidity in light of an evolutionary theory and adaptive learning, we should also cite Bonomo et al. (2003).
} 
monetary innovations and a high level of local interaction between firms. If monetary innovations are too volatile, the economy converges approximately to the rational expectations equilibrium. On the other hand, if the level of local interaction between firms ceases to exist, the economy also converges to the rational expectations equilibrium.

Therefore, the model developed in the subsequent section shares with the contributions by Bonomo et al. (2003) and Saint-Paul (2005) an attempt to derive price rigidity and the implications of incomplete nominal adjustment in terms of monetary policy by building on evolutionary principles. As in Bonomo et al. (2003), we use evolutionary game theory. However, this study introduces two innovations. First, instead of using the replicator dynamics as a way to represent the underlying learning process, we assume a more general evolutionary dynamics based on the hypothesis that firms show a satisficing behavior when they decide to update or not their information sets. Secondly, in our model, the information necessary to determine the optimal price is not freely available, that is, there is a cost for acquiring such information. The model proposed by Saint-Paul (2005) uses the agent-based computational method and, therefore, its results are obtained by numerical simulations. This method allows the author to deal with a wide range of rules of thumb for price setting and also to explicitly explore the effects of local interaction between the agents and those of a specific process for monetary realization, an $\mathrm{AR}(1)$, on price rigidity and incomplete nominal adjustment. In our case, we use the standard modeling strategy based on ordinary differential equations and we obtain the results from the qualitative analysis of the phase diagram of the evolutionary dynamics and from the linearization around the equilibrium or equilibria.

\section{Static Equilibrium}

Blanchard and Kiyotaki (1987) develop a complete macroeconomic model based on a monopolistic competition framework, which formally includes money and which can then be used to evaluate the effects of a variation in nominal aggregate demand, approximated by money supply. As the authors themselves admit, this is a static model in which all prices are assumed to be initially equal and set optimally (Blanchard and Kiyotaki, 1987, p. 663). In the model developed subsequently, firms may or may not establish the optimal price depending on their explicitly modeled convenient choices. In fact, the proportion between those that opt for establishing the optimal price and the other firms follows a satisficing dynamics that coevolves with the macroeconomic variables in whose determination it participates. In addition, while the average cost for the establishment of the optimal price is constant in the model proposed by Blanchard and Kiyotaki (1987), in the subsequent model, this cost depends on the number of firms that pay it.

Let us present the model now. In each period, there is a fraction $k$ of the population of firms, which may vary from one period to the next, which set its 
price without knowing all the prices in the economy, that is, these firms adopted a bounded rationality strategy as they decided not to pay the cost necessary to fully know the structure of relative prices. Hence, they are called bounded rationality firms. The remaining fraction, $1-k$, is made up of fully informed firms that paid the cost for obtaining this information, that is, they are firms that adopted the full rationality strategy. These latter firms, following Droste et al. (2002, p. 244), will be referred to as Nash firms. In the present model, the price setting strategy is the unit of evolutionary selection, whose choice by the firms in each period is based on the expected net (cost) benefits.

However, it should be clarified that the choice between the strategies of paying or not paying the cost associated with the establishment of the optimal price is determined in this paper as boundedly rational and evolutionary, instead of derived from an accurate optimization calculation. Considering the choice between paying or not paying the cost associated with optimization as being itself subject to the optimizing calculation would lead to a self-reference or infinite regression problem (Conlisk, 1996). After all, to optimize it is necessary to have perfect information, which involves costs. Thus, the corresponding optimization is not optimal when such cost is ignored. Here is the contradiction: in order not to ignore such cost it is necessary to have it included in the optimization itself, but there is no way of knowing the cost for the acquisition of perfect information before knowing it perfectly.

In this economy, the general price level, $P$, in place in a certain period, is given by the geometric mean of the prices set by Nash firms, $P_{n}$, and the price set by bounded rationality firms, $P_{b}$, i.e.:

$$
P=P_{b}^{k} P_{n}^{1-k}
$$

By taking the model proposed by de Blanchard and Kiyotaki (1987) as benchmark, the price set by Nash firms, which know the actual $P$ value, is:

$$
P_{n}=\alpha P^{a} M^{1-a}
$$

where $\alpha>0$ and $0<a<1$ represent constants. In other words, this price depends on the nominal money stock, $M$, which is public, and also on the general price level, which is not public. Therefore, the optimal price involves a strategic complementarity, since it depends positively on the price level.

By substituting (1) into (2), we obtain the price set by Nash firms taking into account the price set by the firms that adopt the bounded rationality strategy and their fraction (i.e., the distribution of price setting strategies) in the economy:

$$
P_{n}=\left(\alpha P_{b}^{a k} M^{1-a}\right)^{\xi(k)}
$$

where $\xi(k) \equiv 1 /[1-a(1-k)]$. In the language of Droste et al. (2002, p. 244), the price setting strategy of Nash firms is something like a Nash equilibrium in a price 
setting game that is "contaminated" with bounded rationality firms. Therefore, in this model, the strategic complementarity involved in the optimal price has more ramifications than that which is described in the model of Blanchard and Kiyotaki (1987), given that the optimal price depends positively on the price level which, in turn, depends positively on the price set by Nash firms and on the price set by bounded rationality firms.

In fact, by introducing the optimal decision (3) into (1), we can express the general price level as a function of the price set by bounded rationality firms and of the distribution of price setting strategies in the economy, namely:

$$
P=\left[\left(\alpha_{0} M\right)^{(1-a)(1-k)} P_{b}^{k}\right]^{\xi(k)}
$$

where $\alpha_{0}=\alpha^{\frac{1}{1-a}}$. As widely known, in an economy populated only by firms with perfect information we would have $P=\alpha_{0} M$, which is the price level value in the symmetric Nash equilibrium in the price setting game with perfect information. This follows from (4) resulting in $k=0$, i.e., assuming that there are only Nash firms, or that, for any $k \in(0,1]$, bounded rationality firms could set $P_{b}=\alpha_{0} M$.

Let us analyze the effect of monetary changes in this short run, i.e., for a given predetermined distribution of price setting strategies - which does not therefore necessarily correspond to a long-run evolutionary equilibrium. This analysis will be carried out through the elasticity of the general price level relatively to the nominal money stock. By using (4), this elasticity is given by:

$$
\frac{\partial P}{\partial M} \frac{M}{P}=1-\frac{k}{1-a(1-k)} \equiv \varepsilon(k)
$$

Note that $\varepsilon(0)=1$ and $0<\varepsilon(k)<1$ for every $k \in(0,1)$. Therefore, if there are only firms that adopt the Nash strategy, $k=0$, the economy has complete nominal adjustment in the short run, as expected. Also, nominal adjustment will be equally complete in the short run if there are only firms that adopt the bounded rationality strategy, $k=1$, and if they set their prices equally to the price of the symmetric Nash equilibrium. In this situation, equation (4) yields $P=P_{b}=\alpha_{0} M$, as established by the specification of Blanchard and Kiyotaki (1987), and, therefore, unit elasticity is obtained, and equation (5) loses validity. In this context, a crucial issue to be addressed in the subsequent sections concerns the possibility for the firms that adopt the bounded rationality strategy to learn how to set the symmetric Nash equilibrium price $\left(P_{b}=\alpha_{0} M\right)$ by way of a satisficing evolutionary dynamics. Can the exclusive survival of the bounded rationality strategy, $k=1$, and the symmetric Nash equilibrium price emerge as a long-run evolutionary equilibrium?

When there is an intermediate proportion of firms that adopt the bounded rationality strategy, $0<k<1$, the nominal adjustment of the price level is incomplete and, therefore, money is not neutral. Then, the heterogeneous behavior 
across firms leads to the subdiffusion of the optimal price, since not all firms are setting this price. And as the money elasticity of the optimal price is one, the subdiffusion of the optimal price, as described above, renders this money elasticity less than one. In this situation, an expansion (contraction) of the nominal money stock produces an expansion (contraction) of the real output by a less-than-proportional increase (contraction) in the general price level. In addition, it follows from (5) that:

$$
\varepsilon^{\prime}(k)=-\frac{1-a}{[1-a(1-k)]^{2}}<0
$$

Incomplete nominal adjustment in the short run will be higher the larger the number of firms which adopt the bounded rationality strategy - but it should be recalled, however, as shown above, that the nominal adjustment of price level will be equally complete if there are only bounded rationality firms.

The previous analysis of the effects of monetary changes was conducted in a short-run period in which the distribution of price setting strategies is given and may a priori (with non-null measure) not correspond to a long-run evolutionary equilibrium, in which the distribution of strategies is stationary. The following two sections analyze whether a long-run evolutionary equilibrium exists and configures an emergent property (an attractor) of a satisficing learning process, with and without mutation which, by interacting with the macroeconomic dynamics, determines the evolution of proportions in which price strategies are adopted in the population of firms.

\section{An Evolutionary Dynamics without Mutation}

Although the distribution of firms is given in the short run, it varies over time according to an evolutionary dynamics. Initially, let us suppose that the selection process of the price setting strategy by firms is based solely on aspects related to expected payoffs. In the language of evolutionary games, we assume that firms are not mutants, as we are going to clarify in the subsequent section. So, we will suppose firms have a quadratic loss by not setting their prices optimally. Thus, using (3), the loss of a firm that adopts the unbounded rationality strategy can be expressed as follows:

$$
L_{b}=-\beta\left(P_{b}-P_{n}\right)^{2}=-\beta\left[P_{b}-\left(\alpha P_{b}^{a k} M^{1-a}\right)^{\xi(k)}\right]^{2} \equiv L_{b}\left(k, P_{b}\right)
$$

In which $\beta>0$ is a constant. Such loss can be regarded as the expected payoff of the strategy represented by not incurring the update cost of the information set, which is the cost involved in the inference about the general price level.

In turn, as Nash firms set their optimal price they do not suffer any loss if they deviate from it. In order to set the optimal price, they incur the inference cost of the general price level. Since the payment of such cost of heterogeneity 
by a firm allows it to set an optimal price (which is unique), this cost, albeit fixed in its total, regardless of the number of those which pay it, has an average value that increases with the number of firms that choose not to pay it. Formally, we can capture this scale effect by assuming that the average cost (per firm) for perfectly inferring the general price level is a continually differentiable function of the number of firms that choose the bounded rationality strategy, $c(k)$, such that $c(0)>0$ and $c^{\prime}(k)>0$ for every $k \in[0,1]$. Thus, the loss of Nash firms, since they incur non-null average inference costs, is given by:

$$
L_{n}(k)=-c(k)
$$

which can be interpreted as the expected payoff for incurring the update cost of the information set and, therefore, of perfect inference on the general price level.

Consider that a firm $i$, by observing its loss $L_{i}<0$, which is equal to $L_{b}\left(k, P_{b}\right)$ if it has bounded rationality, or $L_{n}(k)=-c(k)$ if it is a Nash firm, compares it with the level of loss $\bar{L}_{i} \leq 0$ which is regarded as the tolerated maximum, henceforth referred to as tolerated loss. ${ }^{8}$ If $\bar{L}_{i} \leq L_{i}$ firm $i$ would not consider changing the strategy regarding the update of its information set. However, if the tolerated loss is exceeded, firm $i$ becomes a potential strategy reviewer. ${ }^{9}$

The tolerated loss of a firm depends, among other things, on specificities of its price setting process. We will assume that this tolerated loss is randomly and independently determined across firms and over time. More specifically, we assume that the tolerated loss $\bar{L}_{i}$ is a random variable with accumulated continuously differentiable distribution function $F: \Re_{-} \rightarrow[0,1]$. Thus, the probability of randomly choosing a firm $i$ whose tolerated loss $\bar{L}_{i}$ is less than or equal to the incurred loss $L_{i}$ is given by $\operatorname{Pr}\left(\bar{L}_{i} \leq L_{i}\right)=F\left(L_{i}\right)$ and, therefore, the probability of a firm $i$, randomly drawn, having a loss whose module is larger than the tolerated loss module is:

$$
\operatorname{Pr}\left(L_{i}<\bar{L}_{i}\right)=1-F\left(L_{i}\right)
$$

In other words, this is the probability for randomly finding a firm $i$ that is not satisfied with its loss and that is revising its choice to update its information set.

Let us suppose that the probability of a firm $i$ choosing an alternative strategy to the one which it had been following is equal to the frequency at which this alternative strategy is adopted by the population of firms. Consequently, considering (8) and (9), the estimated inflow to the subpopulation of bounded rationality firms, that is, the estimate flow of Nash firms that will become bounded rationality firms, is:

\footnotetext{
${ }^{8}$ In Vega-Redondo (1996, p. 91), a level of reference of a payoff like this is called target level of satisfaction.

${ }^{9}$ The derivation of the satisficing dynamics explained ahead follows the strategy of derivation of a general satisficing dynamics found in Vega-Redondo (1996, p. 91).
} 


$$
\left[1-F\left(L_{n}(k)\right)\right] k(1-k)
$$

Analogously, considering equations (7) and (9), the outflow from the subpopulation of bounded rationality firms, i.e., the estimated flow of bounded rationality firms that will turn into Nash firms is given by:

$$
\left[1-F\left(L_{b}\left(k, P_{b}\right)\right)\right](1-k) k
$$

The difference between the inflow (10) and outflow (11) therefore gives us the rate of change of the frequency at which the strategy of not updating the information set is played in the economy in a given time period:

$$
\dot{k}=k(1-k)\left[F\left(L_{b}\left(k, P_{b}\right)\right)-F\left(L_{n}(k)\right)\right]
$$

This differential equation represents a selection dynamics or evolutionary dynamics,${ }^{10}$ which has the property of monotonicity in payoffs ${ }^{11}$ if $F(\cdot)$ is strictly increasing throughout its domain. By assuming that, the proportion at which the choice not to update the information set is adopted increases (decreases) if, and only if, the payoff of such choice exceeds (is exceeded by) the payoff of the choice to update the information set, i.e., if $L_{b}\left(k, P_{b}\right)>L_{n}(k)$, since in this case $F\left(L_{b}\left(k, P_{b}\right)\right)-F\left(L_{n}(k)\right)>(<) 0$. In other words, the proportion of bounded rationality firms increases (decreases) if the module of expected loss of these firms is smaller (larger) than the cost of acquiring the information necessary to establish the optimal price, that is, if the differential of losses between strategies, which is given by

$$
\psi\left(k, P_{b}\right) \equiv L_{b}\left(k, P_{b}\right)-L_{n}(k)=c(k)-\beta\left[P_{b}-\left(\alpha P_{b}^{a k} M^{1-a}\right)^{\xi(k)}\right]^{2}
$$

is strictly positive (negative).

Note that the evolutionary dynamics (12) is parameterized by the price set by bounded rationality firms. Suppose that this price follows an adaptive process:

$$
\dot{P}_{b}=-\gamma\left(P_{b}-P_{n}\right)=-\gamma\left[P_{b}-\left(\alpha P_{b}^{a k} M^{1-a}\right)^{\xi(k)}\right]
$$

where $\gamma>0$ is a constant. The state transition of the economy is therefore determined by system $(12)-(14)$, whose state space is $\Theta=\left\{\left(k, P_{b}\right) \in \Re^{2}: 0 \leq\right.$ $\left.k \leq 1, P_{b}>0\right\}$.

As the bounded rationality strategy consists in not paying the cost of updating the information set, hence using dated information to set a price as close to optimal as possible, the adaptive specification in (14) comes naturally. Even though

\footnotetext{
${ }^{10}$ A detailed exposition and analysis of such dynamics can be obtained, for instance, in Ponti (2002), Vega-Redondo (1996, ch. 4) or Weibull (1995, ch. 4).

${ }^{11}$ Such property plays a role in the modeling of evolutionary processes in social environments, which is analogous to the mechanism of natural selection in biological environments.
} 
the strategic complementarity observed in the optimal price and the coordination problem that derives from it do not allow the bounded rationality strategy to contemporaneously imitate the price set by Nash firms, which paid the cost of knowing the actual structure of relative prices, it is natural that this bounded rationality strategy is translated into a lagged and, hence adaptive, imitation of the behavior of Nash firms. ${ }^{12}$ As described earlier, a key issue that should be addressed in this section and in the subsequent one concerns the possibility of bounded rationality firms learning to set the symmetric Nash equilibrium price by following a satisficing evolutionary dynamics. Does the exclusive survival of the bounded rationality strategy emerge as a long-run evolutionary equilibrium?

For a given value of $k \in[0,1]$, we have $\dot{P}_{b}=0$ if, and only if,

$$
P_{b}-\left(\alpha P_{b}^{a k} M^{1-a}\right)^{\xi(k)}=0
$$

That is, if, and only if, $P_{b}=\alpha_{0} M$. This price, as already mentioned, is that of the symmetric Nash equilibrium corresponding to the price setting game with perfect information.

When $k=0$ or $k=1$ it follows from (12) that $\dot{k}=0$. Then, we have two equilibria with extinction of strategy, an equilibrium $\left(k, P_{b}\right)=\left(0, \alpha_{0} M\right)$ in which there are only firms that use the Nash strategy, and another equilibrium, $\left(k, P_{b}\right)=$ $\left(1, \alpha_{0} M\right)$, with the survival of firms that use the bounded rationality strategy. Since $P=\alpha_{0} M$ when $P_{b}=\alpha_{0} M$, we then infer that the price that emerges is that of the symmetric Nash equilibrium corresponding to the price setting game with perfect information, not only in the equilibrium in which only the Nash strategy survives, but also in the equilibrium where its extinction occurs.

Given the assumption that there exists a strictly positive cost for updating the information set for any distribution of price setting strategies in the economy, there is no mixed strategy equilibrium, that is, without extinction of one of the strategies. Let us suppose by absurd that there is a $k^{*} \in(0,1)$ such that $c\left(k^{*}\right)>0$ and $\dot{k}=0$. Considering system $(12)-(14),\left(k, P_{b}\right)=\left(k^{*}, \alpha_{0} M\right)$ will be an equilibrium if, and only if:

$$
\psi\left(k^{*}, \alpha_{0} M\right)=c\left(k^{*}\right)-\beta\left\{\alpha_{0} M-\left[\alpha\left(\alpha_{0} M\right)^{a k^{*}} M^{1-a}\right]^{\xi\left(k^{*}\right)}\right\}^{2}=0
$$

As $L_{b}\left(k^{*}, \alpha_{0} M\right)=-\beta\left\{\alpha_{0} M-\left[\alpha\left(\alpha_{0} M\right)^{a k^{*}} M^{1-a}\right] \xi\left(k^{*}\right)\right\}^{2}=0$, then $\psi\left(k^{*}, \alpha_{0} M\right)$ $=c\left(k^{*}\right)$. Thus, $\psi\left(k^{*}, \alpha_{0} M\right)=0$ if, and only if, $c\left(k^{*}\right)=0$, which runs counter to the initial assumption that $c\left(k^{*}\right)>0$.

\footnotetext{
${ }^{12}$ Moreover, empirical evidence of price rigidity reported in Section 2 indicates, among other stylized facts, the existence of two types of price setters regarding the time horizon used, namely, the forward-looking and backward-looking price setters. As properly inferred by Mankiw and Reis (2002), according to footnote 4, and tentatively derived in the model developed herein, the provision of appropriate microfoundations for the nominal adjustment of price level to monetary shocks may require better understanding of bounded rationality.
} 
Let us now analyze the local stability properties of these two pure strategy equilibria. The Jacobian matrix of the linearization around the equilibrium $\left(0, \alpha_{0} M\right)$ of system (12)-(14) is:

$$
J\left(0, \alpha_{0} M\right)=\left[\begin{array}{cc}
F(0)-F(-c(0)) & 0 \\
0 & -\gamma
\end{array}\right]
$$

whose eigenvalues are $\lambda_{1}=F(0)-F(-c(0))>0$ and $\lambda_{2}=-\gamma<0$. Then it follows that equilibrium $\left(0, \alpha_{0} M\right)$, characterized by the extinction of the bounded rationality strategy, is a saddle point. The stationary point of this saddle is the positively invariant subspace $\left\{\left(k, P_{b}\right) \in \Theta: k=0\right\}$, which does not belong to the economically relevant state space. Therefore, for any $\left(k, P_{b}\right) \in \Theta-\left\{\left(k, P_{b}\right) \in \Theta\right.$ : $k=0\}$, the economy does not converge to equilibrium $\left(0, \alpha_{0} M\right)$. If there are firms that initially adopt the bounded rationality strategy, this type of behavior will not disappear (Figure 1).

The Jacobian matrix of the linearization around the equilibrium $\left(1, \alpha_{0} M\right)$ of system (12)-(14) is:

$$
J\left(1, \alpha_{0} M\right)=\left[\begin{array}{cc}
F(-c(1))-F(0) & 0 \\
0 & -(1-a) \gamma
\end{array}\right]
$$

whose eigenvalues are $\lambda_{1}=F(-c(1))-F(0)<0$ and $\lambda_{2}=-(1-a) \gamma<0$. Thus, equilibrium $\left(1, \alpha_{0} M\right)$, characterized by the extinction of the Nash strategy, is a local attractor (Figure 1).

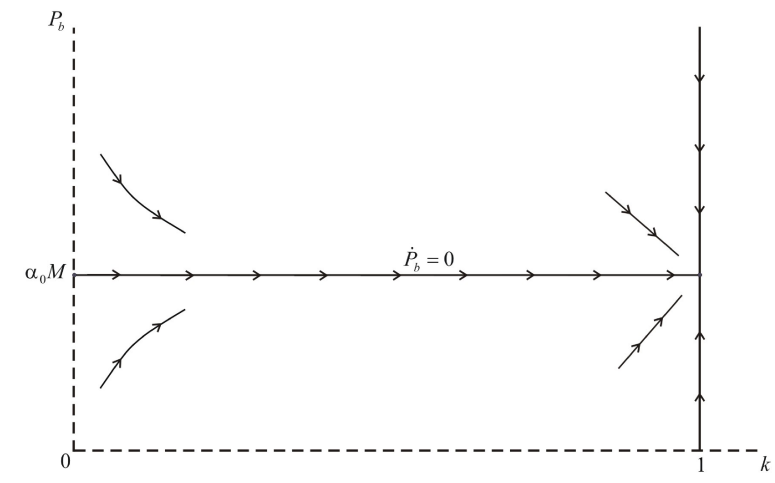

Figure 1

Phase diagram of the evolutionary dynamics without mutation 
From this analysis of local stability through linearization around the two pure strategy equilibria, we can infer that this evolutionary price setting game necessarily takes the economy to a state that is equivalent to the symmetric Nash equilibrium of the price setting game with perfect information. Thus, the extinction of the bounded rationality strategy is not necessary in order for the symmetric Nash equilibrium price to prevail, and this price will prevail even if only the bounded rationality strategy survives. By adapting Samuelson's (1997) description of a situation in which decisions are not guided by complete rationality but rather by rules of thumb, the equilibrium can be reached by an evolutionary dynamics. ${ }^{13}$ In this case in which only the bounded rationality strategy survives, the symmetric Nash equilibrium price emerges not because firms are fully rational, but rather firms seem to be fully rational because an equilibrium has been reached.

As derived in the previous section, even though the nominal adjustment of general price level in response to a monetary shock may be incomplete in the short run, it will necessarily become complete in the long-run equilibrium. Therefore, although money neutrality may be violated in the short run if firms that use the Nash strategy and firms that adopt the bounded rationality strategy coexist, such coexistence - and the nonneutrality of money resulting from it - will not prevail in the long run.

Given that the price setting strategy that can be adopted by a firm, and not the firm itself, is the unit of evolutionary selection, there are two configurations for the evolutionary equilibrium. In both of them, however, the price set by firms - and, then, the general price level - is the symmetric Nash equilibrium price. In the equilibrium in which only the Nash strategy is adopted, the prevalence of this price involves an average cost for the homogenization of price setting which is strictly positive, although it is minimal. Note however that the equilibrium with extinction of the bounded rationality strategy is a saddle point whose stationary point is a positively invariant subspace defined by this extinction, as previously seen. Therefore, there is no possibility of convergence to the equilibrium with extinction of the bounded rationality strategy. If the economy does not depart from a situation in which all firms somehow adopted the Nash strategy, this situation will not be attained as emergent property of the evolutionary dynamics. In the equilibrium in which only the bounded rationality strategy is adopted, the emergence of the symmetric Nash equilibrium price results from an evolutionary learning process after which (i.e., in the long-run equilibrium), the prevalence of this price involves a null average cost. In other words, an evolutionary dynamics based solely on aspects related to expected net benefits leads, in this case, to the elimination of a heterogeneity of strategies that not only leads to the complete

\footnotetext{
${ }^{13}$ In her words: "The behavior that persists in equilibrium then looks as if it is rational, even though the motivations behind it may be quite different. An equilibrium does not appear because agents are rational, but rather agents appear rational because an equilibrium has been reached" (Samuelson, 1997, p. 3).
} 
nominal adjustment of the price level, but also involves a non-null average cost for the economy as a whole.

The fraction of agents that opt for the Nash strategy is like a lighthouse showing where the correct price is for a given configuration (distribution) of price setting behaviors (strategies) in the economy. This lighthouse allows the remaining fraction, composed of agents that do not update their information sets, to correct their path, since they imitate, with a lag, the best responses obtained in the past. In other words, the closer the economy gets to equilibrium $k=1$, the larger the share of general price level determined by the adaptive component, that is, $P=P_{b}^{k} P_{n}^{1-k} \rightarrow P_{b}$ when $k \rightarrow 1^{-}$. Thus, Nash firms increasingly refer to the past price, i.e., $P_{n}=\alpha P^{a} M^{1-a} \rightarrow \alpha P_{b}^{a} M^{1-a}$ when $k \rightarrow 1^{-}$. As bounded rationality firms imitate the best response with a lag, then $P_{b} \rightarrow P_{n} \rightarrow \alpha P_{b}^{a} M^{1-a}$ when $k \rightarrow 1^{-}$. Therefore, as both prices converge to $\alpha P_{b}^{a} M^{1-a}$ when $k \rightarrow 1^{-}$, the general price level that emerges from the steady state is $P=P_{b}=\alpha P_{b}^{a} M^{1-a}$, i.e., $P=P_{b}=\alpha_{0} M$. Finally, by inertia, all eventually copy a past symmetric Nash equilibrium (of the underlying monopolistic competition model), even if the measure of those that deliberately adopt the best response (3) is null. Then, equilibrium $k=1$ can be seen as a convention, i.e., a situation in which, as far as any agent can remember, all have always set their prices at the level given by $\alpha_{0} M{ }^{14}$

It is important to underscore that the analysis of the nominal adjustment in a monopolistic economy proposed in the present paper operates in two dimensions: the macroeconomic one (level of completeness of the nominal adjustment of the general price level) and the microeconomic one (evolutionary selection process for the price setting strategy). Since these two dimensions evolve together over time, a question that is naturally raised regarding dynamic models with heterogeneity and interaction, as the one developed herein, concerns the robustness of a given macrostate (money neutrality) to other possible microeconomic configurations. More specifically, an issue that arises naturally is to what extent the emergent property of money neutrality would be kept if the economy were submitted to another evolutionary dynamics, in which a fraction of firms randomly choose their price setting strategy (mutation) instead of basing this choice on the expected net benefits (selection). According to Samuelson (1997, p. 205), "we can think of selection as capturing the important forces affecting strategy choices, while mutation is a residual, capturing whatever has been excluded when modeling selection". Therefore, after deriving the result of money neutrality for the evolutionary equilibria when there are no experimenting or mutant firms, which are equilibria characterized by the extinction of one of the strategies, one naturally wonders the validity of this neutrality result for the following robustness check: is the extinction of one of the price setting strategies - i.e., emergence, in the evolu-

\footnotetext{
${ }^{14}$ The intuitive idea of convention as an evolutionary equilibrium is borrowed from Young (1998), although this author deals with such notion in a formal structure that is different from the one used in the present paper.
} 
tionary equilibrium, of a homogenous behavior - a condition that is necessary for the existence of money neutrality? As described in detail in the next section, the answer is no.

\section{An Evolutionary Dynamics with Mutation}

Considering the possibility of experimentation, the way it can be rationalized in evolutionary games, allows us to make the model even more realistic. Depending on the biological system, a mutation in an evolutionary game can be interpreted as a genetic change, a cell differentiation, a change in gene expression, an incidental or deliberate change in transmission or a learning error. Therefore, in a biological context, mutation is interpreted ipsis literis, consisting of random changes in genetic codes. In economic contexts, however, as pointed out by Samuelson (1997, ch. 7), the term mutation refers to a situation in which an agent changes his strategy at random. Hence, in economic situations, mutation concerns a situation in which an agent experiences a new strategy or is replaced by a new agent who, being unfamiliar with the game, initially chooses a strategy at random. In the context of the evolutionary process of choosing a price setting strategy analyzed in the present paper, it is quite reasonable to interpret mutation as the entry of new firms or as exogenous disturbances in the decision-making process regarding price setting by existing firms, which certainly confer more realism to the model's premises. Therefore, the driving factor for the robustness check represented by the possibility of mutation can be alternatively expressed as follows: is the nonoccurrence of phenomena such as the entry of new firms or exogenous disturbances in the decision-making process regarding price setting by existing firms a sine qua non for the existence of money neutrality in the evolutionary equilibrium? As shown further ahead, the answer is no.

To test the robustness of results obtained in the previous section, we assume that the evolutionary dynamics (12), which represents the mechanism of selection at work in this economic environment, operates in the presence of a type of disturbance that is analogous to the process of mutation in natural environments. In the previous section, we assumed that the choice of the price setting strategy was based on aspects related to expected payoffs, and that mutant agents did not exist, i.e., firms that chose strategies at random without taking into account the loss differential expected from price setting strategies. ${ }^{15}$

Nevertheless, the way whereby we included the possibility of mutation differs from that one adopted by Saint-Paul (2005). As summarized in Section 2, SaintPaul models a macroeconomics populated by imperfectly rational firms which are hypothetically unable to compute their optimal rule for price setting, thus having

\footnotetext{
15 "Unlike the selection mechanism, there is little reason to believe that mutations have a particularly strong connection with the payoffs of the game. Thus mutations are conventionally modeled as being completely random, in the sense that they may switch a player to any of the existing strategies and are unaffected by payoffs" (Samuelson, 1997, p. 206).
} 
to experience rules of thumb. This experimentation process occurs in the following way. Each firm randomly chooses a rule to be used for a given time period, after which it tries, with certain probability, a new rule. This new rule is chosen using one of the following ways. The new rule is randomly selected from the available rules or results from a local mutation of the rule being used. This mutation is caused by a random disturbance in the rule being used.

According to the formulation developed in this paper, firms can set the optimal price by paying the cost of updating their information set, and therefore, boundedrationality and Nash firms may coexist. In addition, in this section, the selection dynamics (12) operates with a noise, given that some firms choose their price setting strategy regardless of the expected payoff. Then, whereas in Saint-Paul (2005) all firms choose a new rule without considering a payoff through a local random process (disturbance in the rule being used) or global process (equiprobable selection from the available rules), in this section, only a fraction of firms chooses their strategies without considering a payoff, which is obtained by a global random process.

More precisely, let $\theta \in(0,1)$ be the number (measure) of mutant firms that choose a strategy at a given time regardless of the expected losses (payoffs). Of this amount of mutant firms, $\theta(1-k)$ are Nash firms and $\theta k$ are bounded rationality firms. Suppose that a mutant firm chooses one of the two price setting strategies (Nash or bounded rationality) with equal probability. Therefore, $\theta(1-k) \frac{1}{2}$ Nash firms and $\theta k \frac{1}{2}$ bounded rationality firms will effectively change strategies. So, the net (positive or negative) flow of mutant firms that will become bounded rationality firms at a given time is given by:

$$
\theta(1-k) \frac{1}{2}-\theta k \frac{1}{2}=\theta\left(\frac{1}{2}-k\right)
$$

Following Gale et al. (1995), this noise may be added to the selection dynamics (12) giving rise to an evolutionary dynamics with mutation, denoted as follows:

$$
\dot{k}=(1-\theta) k(1-k)\left[F\left(L_{b}\left(k, P_{b}\right)\right)-F\left(L_{n}(k)\right)\right]+\theta\left(\frac{1}{2}-k\right)
$$

The state transition of the economy is then determined by system (12.A) - (14), whose state space still is $\Theta=\left\{\left(k, P_{b}\right) \in \Re^{2}: 0 \leq k \leq 1, P_{b}>0\right\}$.

Unlike the dynamics analyzed in the previous section, system (12.A)-(14) does not have pure strategy equilibria, as when $k=0$ or $k=1$ it follows from (12.A) that $\dot{k}=\theta / 2>0$ and $\dot{k}=-\theta / 2<0$, respectively.

As already demonstrated, for a given $k$ in (14), condition $\dot{P}_{b}=0$ is satisfied if, and only if $P_{b}=\alpha_{0} M$. Since $L_{b}\left(k, \alpha_{0} M\right)=-\beta\left\{\alpha_{0} M-\left[\alpha\left(\alpha_{0} M\right)^{a k} M^{1-a}\right] \xi(k)\right\}^{2}=$ 0 and $L_{n}(k)=-c(k)$, (12.A) becomes: 


$$
\dot{k}=(1-\theta) k(1-k)[F(0)-F(-c(k))]+\theta\left(\frac{1}{2}-k\right) \text { for } P_{b}=\alpha_{0} M
$$

Considering this equation, we obtain $\dot{k}=0$ if, and only if

$$
(1-\theta) k(1-k)[F(0)-F(-c(k))]=\theta\left(k-\frac{1}{2}\right)
$$

Taking the limit of both sides of (20) when the mutation rate tends towards zero $\left(\theta \rightarrow 0^{+}\right)$we get:

$$
k(1-k)[F(0)-F(-c(k))]=0
$$

an equality that is satisfied, for $c(k)>0$, if $k=0$ or $k=1$, as $F(0)-F(-c(k))>0$. In other words, if the mutation rate is zeroed, the two pure strategy equilibria of the evolutionary dynamics without mutation reappear, as pointed out in Section 4.

Since, hypothetically, $\theta \in(0,1)$, for any $k \in(0,1)$, condition (20) can be rewritten as follows:

$$
\phi(k)=F(0)-F(-c(k))-\left(\frac{\theta}{1-\theta}\right) \frac{(k-1 / 2)}{k(1-k)}=0
$$

Note that $\phi(k)>0$ for any $k \in(0,1 / 2]$, in particular, $\phi(1 / 2)=F(0)-$ $F(-c(1 / 2))>0$. Furthermore, $\lim _{k \rightarrow 1^{-}} \phi(k)=F(0)-F(-c(1))-\infty=-\infty$. Using the intermediate value theorem, we then infer that there is at least one $k^{*} \in$ $(1 / 2,1)$ such that $\phi\left(k^{*}\right)=0$. Therefore, the evolutionary dynamics with mutation (12.A)-(14) has at least one equilibrium $\left(k, P_{b}\right)=\left(k^{*}, \alpha_{0} M\right)$, in which there is prevalence of firms that use the bounded rationality strategy. Similarly to the dynamics without mutation, the price in the steady state is the symmetric Nash equilibrium price of the price setting game with perfect information, in such a way that this state is characterized by complete nominal adjustment of the price level and, therefore, by money neutrality.

Moreover, if there is only one mixed strategy equilibrium $\left(k, P_{b}\right)=\left(k^{*}, \alpha_{0} M\right)$ we should have:

$$
\phi^{\prime}\left(k^{*}\right)=F^{\prime}\left(c\left(k^{*}\right)\right) c^{\prime}\left(k^{*}\right)-\left(\frac{\theta}{1-\theta}\right)\left[\frac{k^{*}\left(1-k^{*}\right)+\left(1 / 2-k^{*}\right)\left(1-2 k^{*}\right)}{\left[k^{*}\left(1-k^{*}\right)\right]^{2}}\right]<0
$$

as $\phi(1 / 2)=c(1 / 2)>0$ and $\lim _{k \rightarrow 1^{-}} \phi(k)=-\infty$, function $\phi(k)$ crosses the axis $k$ in $k^{*}$ in a top-down manner. 
As previously shown, when $\theta \rightarrow 0^{+}$there is a bifurcation, characterized by the disappearance of the mixed strategy equilibrium (or equilibria) and emergence of two pure strategy equilibria. In addition, if all firms were mutants $(\theta=1)$, then the evolutionary dynamics with mutation (12.A) would be given by $\dot{k}=\theta(1 / 2-k)$, whose equilibrium would be $k=1 / 2$. If all firms chose their price setting strategy regardless of the expected losses (payoffs), more specifically, if they chose a strategy at random and with equal probability, the distribution of equilibrium strategies would be characterized by equal shares of the two types of firms.

By supposing that there is only one mixed strategy equilibrium, we then analyze its local stability properties. The Jacobian matrix of the linearization around an equilibrium $\left(k^{*}, \alpha_{0} M\right)$ of system (12.A)-(14) is:

$$
J\left(k^{*}, \alpha_{0} M\right)=\left[\begin{array}{cc}
(1-\theta)\left(( 1 - 2 k ^ { * } ) \left(F(0)-F\left(-c\left(k^{*}\right)\right)\right.\right. & \\
\left.+k^{*}\left(1-k^{*}\right) F^{\prime}(\cdot) c^{\prime}\left(k^{*}\right)\right)-\theta & 0 \\
0 & -(1-a) \gamma \xi\left(k^{*}\right)
\end{array}\right]
$$

whose eigenvalues are $\lambda_{1}=(1-\theta)\left(\left(1-2 k^{*}\right)\left(F(0)-F\left(-c\left(k^{*}\right)\right)+k^{*}\left(1-k^{*}\right) F^{\prime}\right.\right.$ $\left.\left(-c\left(k^{*}\right)\right) c^{\prime}\left(k^{*}\right)\right)-\theta$ and $\lambda_{2}=-(1-a) \gamma \xi\left(k^{*}\right)<0$. We can demonstrate that if there is only one equilibrium and therefore condition (22) holds, then $\lambda_{1}<0 .{ }^{16}$ That is, if there is one and only one mixed strategy equilibrium in the evolutionary dynamics with mutation this is a local attractor (cf. Figure 2). Thus, even in the presence of this changing behavior, there is convergence of the price setting game with perfect information to the symmetric Nash equilibrium. However, with the inclusion of mutant firms, the Nash equilibrium is achieved without extinction of one of the strategies.

To conclude this section, it should be highlighted that the inclusion of mutation in the evolutionary dynamics implies, by excluding the possibility of extinction of price setting strategies, the survival of heterogeneous strategies in the long run. Therefore, mutation causes heterogeneity shocks which are responsible for the existence of an average cost for the updating of the information set which are non-null in the long run.

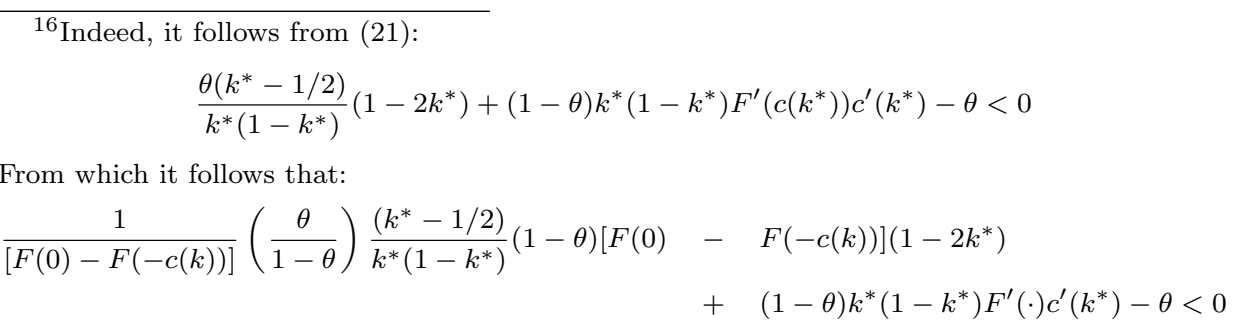

Using (18.A), it then follows that:

$$
(1-\theta)[F(0)-F(-c(k))]\left(1-2 k^{*}\right)+(1-\theta) k^{*}\left(1-k^{*}\right) c^{\prime}\left(k^{*}\right)-\theta<0
$$




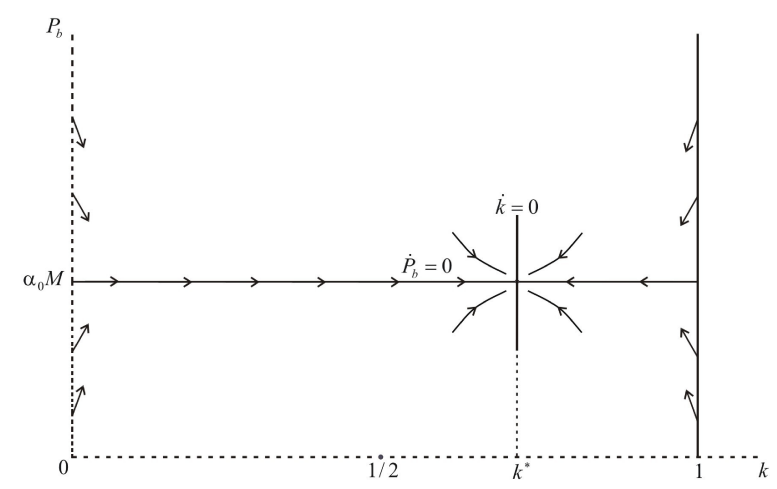

Figure 2

Phase diagram of the evolutionary dynamics with mutation

\section{Final Remarks}

The present paper developed an evolutionary dynamics in order to provide microfoundations for (in)complete nominal adjustment. To do that, we assumed that the information necessary to determine the optimal price is not freely available, i.e., there is a cost for acquiring such information. However, the process of choosing between paying and not paying the cost associated with optimization was regarded to be boundedly rational and evolutionary rather than derived from an accurate optimization calculation. This choice was considered as an individual satisficing learning process, in which each firm adjusts its price setting strategy in a macroeconomic environment under constant change, taking into account its past successes and failures in terms of deviation from a tolerable profit loss.

We then analyzed the effect of monetary changes in the short run, that is, for a given predetermined distribution of price setting strategies - which is hence not necessarily that which corresponds to a dynamic evolutionary equilibrium. If there are only Nash firms, the macroeconomics has complete nominal adjustment in the short run, as expected. In addition, nominal adjustment in the short run will be equally complete if there are only firms that adopt the bounded rationality strategy. When Nash and bounded rationality firms coexist, nominal adjustment is incomplete. In this situation, an expansion (contraction) of the nominal money stock, by causing a less-than-proportional increase (decrease) in the general price level, produces an expansion (contraction) of output, with incomplete nominal adjustment being larger, the larger the proportion of firms that adopt the bounded rationality strategy.

Assuming that firms follow a satisficing behavior when choosing between the price setting strategies, we derived an evolutionary dynamics that, by interacting 
with the macroeconomic dynamics, determined the joint evolution of the distribution of these strategies and of the macroeconomic variables. We showed that the survival of the Nash strategy is not a sine qua non for complete nominal adjustment in the long run, i.e., the economy can converge to an evolutionary equilibrium in which there exist only firms that adopt the bounded rationality strategy and, in spite of that, money will be neutral in the long run.

To test the robustness of this result, we included a form of experimentation analogous to the process of mutation in natural environments in the evolutionary dynamics. We relaxed the assumption that the choice of the price setting strategy is based solely on aspects related to the expected payoff, thus assuming that there are mutant firms that choose price setting strategies at random without considering the payoff differential expected from the available strategies. In this evolutionary dynamics with mutation, we showed that there are only mixed strategy equilibria, in which there is a prevalence of firms that adopt the bounded rationality strategy. However, similarly to the evolutionary dynamics without mutation, the price in these steady states is the symmetric Nash equilibrium price of the price setting game with complete information, so that these states are characterized by complete nominal adjustment of the general price level and, therefore, by money neutrality.

\section{References}

Akerlof, G. \& Yellen, J. (1985). A near-rational model of the business cycle, with wage and price inertia. Quarterly Journal of Economics, 100(5):823-38.

Álvares, L., Dhyne, E., Hoeberichts, M., Kwapil, C., Bihan, H., Lünemann, P., Martins, F., Sabbatini, R., Stahl, H., Vermeulen, P., \& Vilmunen, J. (2006). Sticky prices in the Euro area: A summary of new micro evidence. Journal of the European Economic Association, 4(2-3):575-584.

Amirault, D., Kwan, C., \& Wilkinson, G. (2006). A survey of price-setting behaviour of Canadian companies. Bank of Canada Working Paper 2006-35, September.

Bils, M. \& Klenov, P. (2004). Some evidence on the importance of sticky prices. Journal of Political Economy, 112(5):947-85.

Blanchard, O. \& Kiyotaki, N. (1987). Monopolistic competition and the effects of aggregate demand. American Economic Review, 77(4):647-66.

Bonomo, M., Carrasco, V., \& Moreira, H. (2003). Aprendizado evolucionário, inércia inflacionária e recessão em desinflações monetárias. Revista Brasileira de Economia, 57(4):663-681.

Calvo, G. (1983). Staggered prices in a utility maximizing framework. Journal of Monetary Economics, 12(September):383-398. 
Caplin, A. \& Spulber, D. (1987). Menu costs and the neutrality of money. Quarterly Journal of Economics, 102(4):703-25.

Carroll, C. (2006). The epidemiology of macroeconomic expectations. In Blume, L. \& Durlauf, S., editors, The Economy as an Evolving Complex System, III. Oxford University Press, Oxford.

Conlisk, J. (1996). Why bounded rationality? Journal of Economic Literature, XXXIV(June):669-700.

Droste, E., Hommes, C., \& Tuinstra, J. (2002). Endogenous fluctuations under evolutionary pressure in Cournot competition. Games and Economic Behavior, 40:232-69.

Eichenbaum, M. \& Fisher, J. (2004). Evaluating the Calvo model of sticky prices. NBER Working Paper 10617, June.

Fischer, S. (1977). Long-term contracts, rational expectations and the optimal money supply rule. Journal of Political Economy, 85(1):191-205.

Gale, J., Binmore, K., \& Samuelson, L. (1995). Learning to be imperfect: The ultimatum game. Games and Economic Behavior, 8:56-90.

Lucas, R. E. (1972). Expectations and the neutrality of money. Journal of Economic Theory, 4(April):103-24.

Lucas, R. E. (1973). Some international evidence on output-inflation tradeoffs. American Economic Review, 63(June):326-34.

Mankiw, N. (1985). Small menu costs and large business cycles. Quarterly Journal of Economics, 10(2):529-38.

Mankiw, N. \& Reis, R. (2002). Sticky information versus sticky prices: A proposal to replace the New Keynesian Phillips curve. Quarterly Journal of Economics, 117(4):1295-1328.

Ponti, G. (2002). Continuous-time evolutionary dynamics: Theory and practice. Research in Economics, 54:187-214.

Roberts, J. (1995). New Keynesian economics and the Phillips curve. Journal of Money, Credit and Banking, 27(November):975-84.

Rotemberg, J. (1982). Sticky prices in the United States. Journal of Political Economy, 90(6):1187-1211.

Saint-Paul, G. (2005). Some evolutionary foundations for price level rigidity. American Economic Review, 95(3):765-779. 
Samuelson, L. (1997). Evolutionary Games and Equilibrium Selection. The MIT Press, Cambridge, MA.

Simon, H. (1987). Satisficing. In Eatwell, J., Milgrate, M., \& Newman, P., editors, The New Palgrave. Macmillan, London.

Taylor, J. (1980). Aggregate dynamics and staggered contracts. Journal of Political Economy, 88(1):1-23.

Taylor, J. (1999). Staggered price and wage setting in macroeconomics. In Taylor, J. \& Woodford, M., editors, Handbook of Macroeconomics, volume I, pages 1009 1050. Elsevier Science, New York.

Vega-Redondo, F. (1996). Evolution, Games and Economic Behaviour. Oxford University Press, Oxford, UK.

Weibull, J. W. (1995). Evolutionary Game Theory. The MIT Press, Cambridge, MA.

Woodford, M. (2003). Imperfect common knowledge and the effects of monetary policy. In Aghion, R., Frydman, J., Stiglitz, J., \& Woodford, M., editors, Knowledge, Information and Expectations in Modern Macroeconomics: Essays in Honor of Edmund Phelps, pages 25-58. Princeton University Press, Princeton.

Young, H. P. (1998). Individual Strategy and Social Structure: An Evolutionary Theory of Institutions. Princeton University Press, Princeton.

Zbaracki, M., Ritson, M., Levy, D., Dutta, S., \& Bergen, M. (2004). Managerial and customer costs of price adjustment: Direct evidence from industrial markets. The Review of Economics and Statistics, 86(2):514-533. 